\title{
Evaluated Result Relationship
}

National Cancer Institute

\section{Source}

National Cancer Institute. Evaluated Result Relationship. NCI Thesaurus. Code C93463.

Specifies the link between an adverse event causal assessment and the observation result evaluated as a possible cause. 